\title{
Analisis Sifat Mekanik Hasil Pengelasan SMAW dengan Akar Las Tig dan Las SMAW pada Pipa API 5L
}

\author{
Muas $\mathbf{M}^{1^{*}}$, Muhammad Arsyad Suyuti², Rasul ${ }^{3}$, Patta Hajji ${ }^{4}$ \\ 1,2.3.4 Jurusan Teknik Mesin, Politeknik Negeri Ujung Pandang, Makassar 90245, Indonesia \\ *muas@poliupg.ac.id@poliupg.ac.id
}

\begin{abstract}
The purpose of this research is to know the mechanical properties of the welds due to the current variation of welding joint API $5 L$ using TIG and SMAW welding root methods. Preparation of specimens of pipe API 5L PSL1 grade X56 (Ø $177.8 \mathrm{~mm}$, length $200 \mathrm{~mm}$, width $7 \mathrm{~mm}$ ), then specimens preparation were made in a single $V 60^{\circ}$, root gap $2 \mathrm{~mm}$, root face $2 \mathrm{~mm}$. Filling the welding roots with TIG welding and SMAW using electrodes E7018 with a current variation 70A, 80A, 90A. Mechanical tests consist of tensile, bending and hard test. The results showed that the quality of a good TIG root weld at 70A, the highest tensile strength of the weld joint $52.27 \mathrm{kgf} / \mathrm{mm}^{2}$ (70A), the highest hardnest 164,217 HRB (90A), the bending strength $1.123,061 \mathrm{~N} / \mathrm{mm}^{2}(70 \mathrm{~A})$ using face bend method and 1,172,959 $\mathrm{N} / \mathrm{mm}^{2}$ with root bend. In SMAW root welding, the highest tensile strength $54.27 \mathrm{kgf} / \mathrm{mm}^{2}(70 \mathrm{~A})$, the highest hardnest $158.717 \mathrm{HRB}(70 \mathrm{~A})$, the highest bending strength 1.115,611 N/mm (70 A) using face bend method, and $1.161,748 \mathrm{~N} / \mathrm{mm}^{2}$ with root bend.
\end{abstract}

Keywords: : SMAW,TIG,welding root, Pipe API 5L, mechanical test.

\begin{abstract}
Abstrak: Penelitian ini bertujuan untuk mengetahui sifat mekanik las terhadap variasi arus las pada sambungan pengelasan pipa API 5L dengan menggunakan metode akar las TIG dan SMAW. Pembuatan specimen pengujian pipa API 5L PSL1 grade X56 (Ø 177,8 mm, panjang $200 \mathrm{~mm}$, lebar $7 \mathrm{~mm}$ ) kemudian spesimen dibuatkan kampuh V sudut $60^{\circ}$, celah akar $2 \mathrm{~mm}$, tinggi akar $2 \mathrm{~mm}$. Pengisian akar las dengan las TIG dan las SMAW menggunakan elektroda E7018 dengan variasi arus 70A, 80A, 90A. Spesimen diuji mekanik berupa uji tarik, tekuk dan keras. Hasil menunjukkan bahwa kualitas sambungan akar las TIG yang baik pada arus 70A, kekuatan tarik sambungan las tertinggi pada arus 70 A sebesar $52,27 \mathrm{kgf} / \mathrm{mm}^{2}$, kekerasan tertinggi pada arus 90 A sebesar $164,217 \mathrm{HRB}$, kekuatan lentur tertinggi pada arus $70 \mathrm{~A}$ sebesar $1.123,061 \mathrm{~N} / \mathrm{mm}^{2}$ penekanan face bend dan $1.172,959 \mathrm{~N} / \mathrm{mm}^{2}$ penekanan root bend. Pada pengelasan akar las SMAW kekuatan tarik sambungan las tertinggi pada arus $70 \mathrm{~A}$ sebesar $54,27 \mathrm{kgf} / \mathrm{mm}^{2}$, kekerasan tertinggi pada arus 70 A sebesar 158,717 HRB, kekuatan lentur tertinggi pada arus 70 A sebesar 1.115,611 N/mm penekanan face bend dan $1.161,748 \mathrm{~N} / \mathrm{mm}^{2}$ penekanan root bend.. (Font 9)
\end{abstract}

Kata kunci : Las SMAW, Las TIG, Pipa API 5L, akar las, pengujian mekanik

\section{PENDAHULUAN}

Jenis pipa yang banyak digunakan dalam sistem perpipaan pada pipeline dan piping adalah pipa jenis API 5L. Pipa jenis ini cocok digunakan untuk aliran gas, air dan minyak. Spesifikasi API 5L merupakan standarisasi sistem transportasi pipa, bahan, perlatan dan struktur lepas pantai untuk minyak buni, petrokimia dan industri gas alam. Teknik penyambungan yang banyak digunakan adalah pengelasan.[1]

Kerusakan yang sering timbul pada penyambungan pengelasan yang menggunakan pipa API 5L yaitu terjadi retak pada sambungan las yang disebabkan oleh gempa bumi atau pergeseran tanah yang menyebabkan terjadinya tegangan geser sehingga tekanan pipa dari luar meningkat dan bisa menyebabkan keretakan bahkan kebocoran.[2]

Beberapa hal yang mempengaruhi pelaksanaan proses pengelasan : alat dan bahan yang diperlukan, urutan pelaksanaan, pemilihan mesin las, penunjukan juru las, dan pemilihan elektroda serta jenis kampuh. Pengelasan berdasarkan cara kerja dapat diklasifikasikan dalam tiga kelompok yakni pengelasan cair, pengelasan tekan dan pematrian. Untuk penyambungan pipa API 5L pengelasan yang digunakan adalah pengelasan cair. Pengelasan cair adalah suatu cara pengelasan dimana benda yang akan disambung dipanaskan sampai mencair dengan sumber energi panas. 
Pengelasan cair yang umum diginakan adalah las TIG (Tangsten Inert Gas) dan SMAW (Shielded Metal Arc Welding). $[\mathbf{3}, \mathbf{4}]$

Dua faktor utama yang mempengaruhi hasil pengelasan yaitu kualitas pengisian akar las, dan kuat arus. Pengisian akar dengan las TIG dan SMAW memiliki karakteristik yang berbeda terutama dalam hal sifat mekaniknya. Begitupula dalam penggunaan arus, apabila menggunakan arus yang sangat rendah akan mengakibatkan penyalaan busur listrik menjadi sulit, sehingga elektroda dan bahan dasar tidak mampu untuk meleleh sempurna dan hasilnya akan membentuk rigi-rigi las yang kecil dan tidak rata kemudian penembusan dangkal.[5,6] Begitupun sebaliknya apabila menggunakan arus yang sangat tinggi akan mengakibatkan permukaan las yang lebih lebar dan penembusan yang dalam dikarenakan elektroda mencair terlalu cepat sehingga kekuatan tarik yang rendah dan menambah kerapuhan hasil pengelasan.

Dengan mengetahui sifat mekanik las terhadap variasi arus las dengan metode pengisian akar las TIG dan SMAW pada sambungan pengelasan pipa API $5 \mathrm{~L}$ diameter $177,8 \mathrm{~mm}$ dan tebal $7 \mathrm{~mm}$, diharapkan dapat diketahui parameter-parameter kualitas pengelasan yang optimum.

\section{METODE PENELITIAN}

Penelitian dilaksanakan di Bengkel Mekanik dan Laboratorium Mekanik Jurusan Teknik Mesin Politeknik Negeri Ujung Pandang. Sebelum melakukan pembuatan specimen pengujian, terlebih dahulu dilakukan pengujian terhadap bahan dasar/logam induk untuk mengetahui spesifikasi dan gradenya dan memastikan bahwa material tersebut adalah pipa API 5L.

Memotong benda kerja yakni pipa API 5L Ø 177,8 mm dengan ukuran panjang $200 \mathrm{~mm}$, dan membuat kampuh $\mathrm{V}$ sudut $60^{\circ}$, jarak celah $2 \mathrm{~mm}$, tinggi akar $2 \mathrm{~mm}$. Pengelasan benda kerja dengan akar las TIG dan las SMAW, dilanjutkan dengan pengelasan covering dengan las SMAW. Variasi arus pengelasan : $70 \mathrm{~A}, 80 \mathrm{~A}$ dan $90 \mathrm{~A}$. Elektroda yang digunakan E7018.

Pembuatan specimen pengujian sesuai standar pengujian mekanik. Jumlah specimen dalam penelitian ini adalah 36 buah untuk masing-masing kelompok arus pengelasan ditambah 2 buah sampel normal material (logam induk).

Pengujian tarik dilakukan untuk mengetahui kekuatan tarik benda uji dan perbandingan nilai kekuatannya dengan raw material serta untuk mengetahui letak putusnya specimen tersebut. Pengujian kekerasan dilakukan untuk mengetahui kekerasan material pada daerah las, HAZ dan logam induk. Pengujian tekuk untuk mengetahui sejauh mana sifat ulet dan kegetasan dari bahan serta mengetahui kemampuan deformasi hasil pengelasan. [2]

Setelah melakukan uji tarik, uji kekerasan dan uji tekuk terhadap semua sampel uji maka diperoleh data tabel yang akan dianilisa secara statistic sehingga diperoleh data yang bersifat kuantitatif.

\section{HASIL DAN PEMBAHASAN}

\section{A. Kekerasan}

Pada pengelasan TIG pipa API 5L arus 90 A, distribusi kekerasannya relative merata pada logam induk dan HAZ serta memiliki kekerasan tertinggi pada logam las sehingga kualitas kekerasan hasil pengelasan lebih baik dibandingkan dengan arus $70 \mathrm{~A}$ dan $80 \mathrm{~A}$. Hal ini dapat dilihat pada grafik 3.1.

Sedangakan pengelasan SMAW, distribusi kekerasan merata pada logam induk dan HAZ dengan arus $70 \mathrm{~A}$, kondisi ini kekerasan tertinggi pada logam las, sehingga kualitas kekerasan hasil pengelasan lebih baik dibandingkan arus 80 A dan 90 A. Distribusi kekerasan dapat dilihat pada Gambar 3.1 dan 3.2 
39 Muas M, Muhammad Arsyad Suyuti, Rasul, Patta Hajji. Analisis Sifat Mekanik Hasil Pengelasan SMAW dengan Akar Las Tig dan Las SMAW pada Pipa API 5L
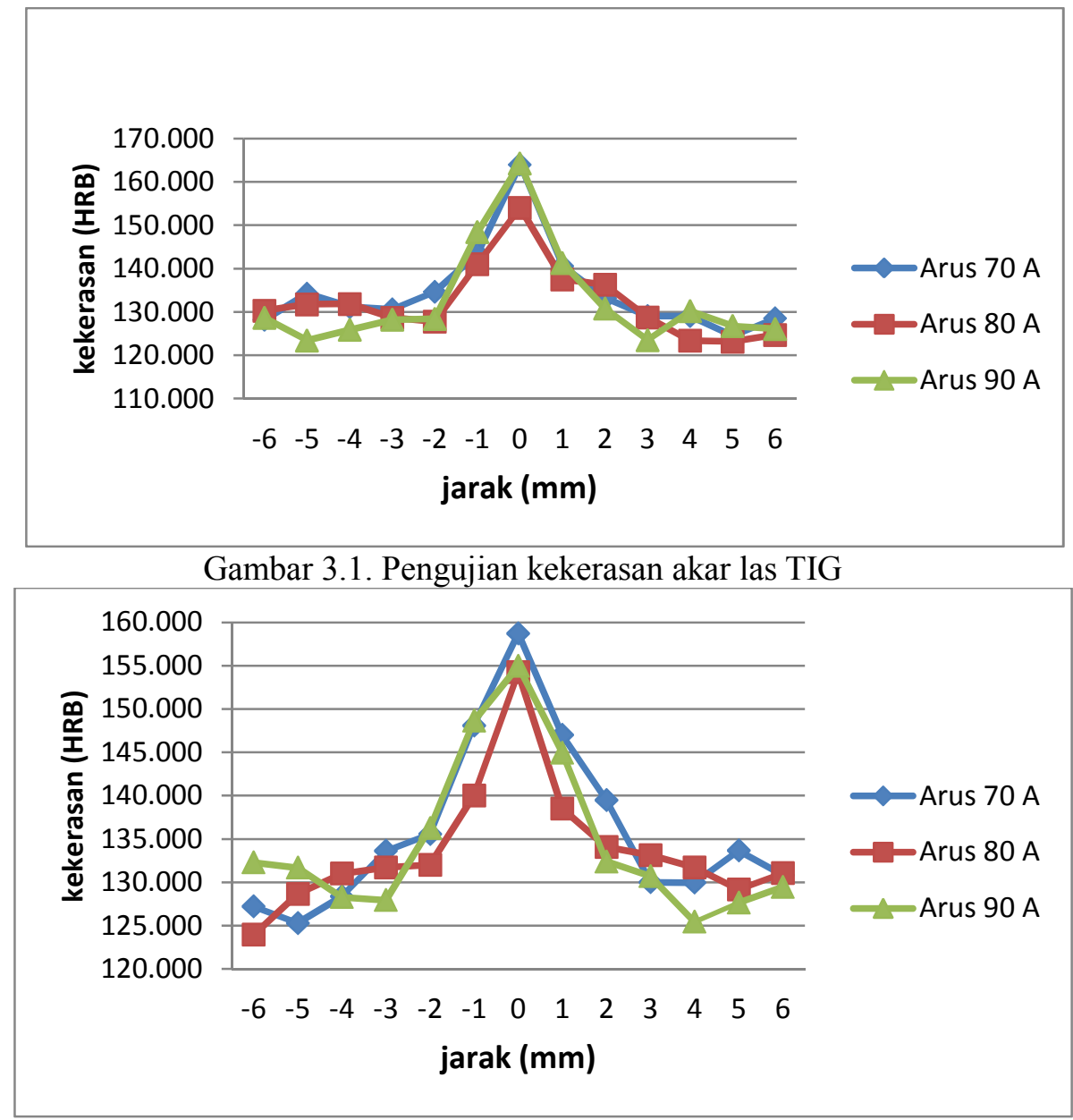

Gambar 3.2. Pengujian kekerasan akar las SMAW

KekKekerasan maksimum menggunakan akar las TIG dan SMAW secara berurrut sebesar 164,217 HRB pada arus $90 \mathrm{~A}$ dan $158,717 \mathrm{HRB}$ pada arus $70 \mathrm{~A}$.

\section{B. Kekuatan tarik dan lentur}

Kekuatan tarik akar las TIG tertinggi sebesar $52,27 \mathrm{kgf} / \mathrm{mm}^{2}$ pada arus 70 A. Sedangkan pada SMAW tertinggi pada arus 70 A sebesar $54,27 \mathrm{kgf} / \mathrm{mm}^{2}$. Hubungan antara besar arus dan besarnya kekuatan tarik dapat dilihat pada gambar 3.3.

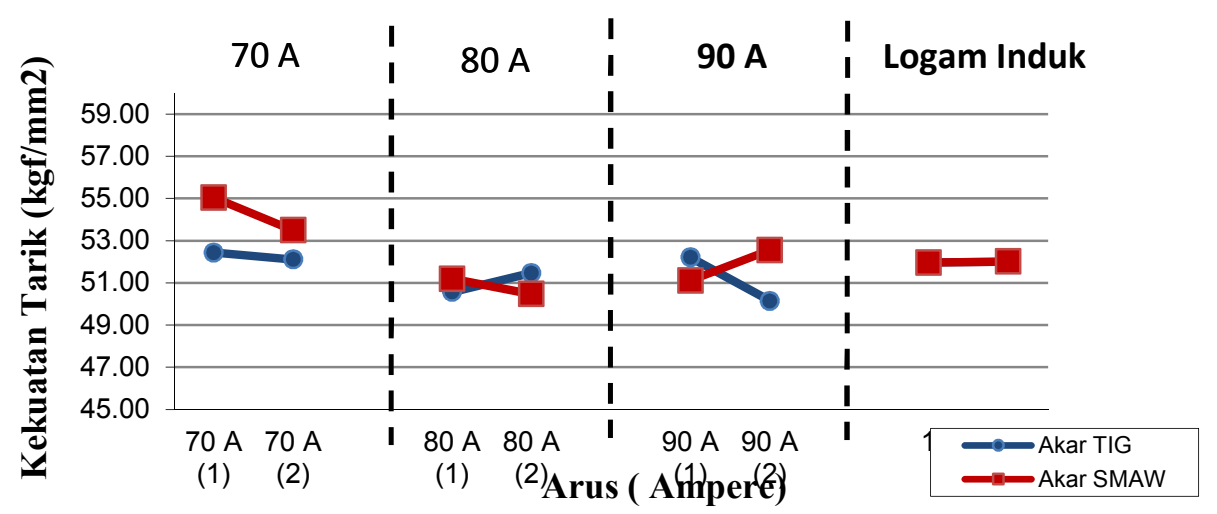

Gambar 3.3. Hubungan kuat arus dan kekuatan tarik las TIG dan SMAW 
Untuk kekuatan lentur, pada las TIG, dengan menggunakan metode penekanan face bend diperoleh kekuatan lentur tertinggi pada arus $70 \mathrm{~A}$ sebesar $1.123,061 \mathrm{~N} / \mathrm{mm}^{2}$ dan $1.172,959 \mathrm{~N} / \mathrm{mm}^{2}$ dengan penekanan root bend. Pada las SMAW kekuatan lentur tertinggi pada arus 70 A sebesar 1.115,611 $\mathrm{N} / \mathrm{mm}^{2}$ penekanan face bend dan $1.161,748 \mathrm{~N} / \mathrm{mm}^{2}$ penekanan root bend Hubungan antara besar arus dan besarnya kekuatan lentur dapat dilihat pada gambar 3.4

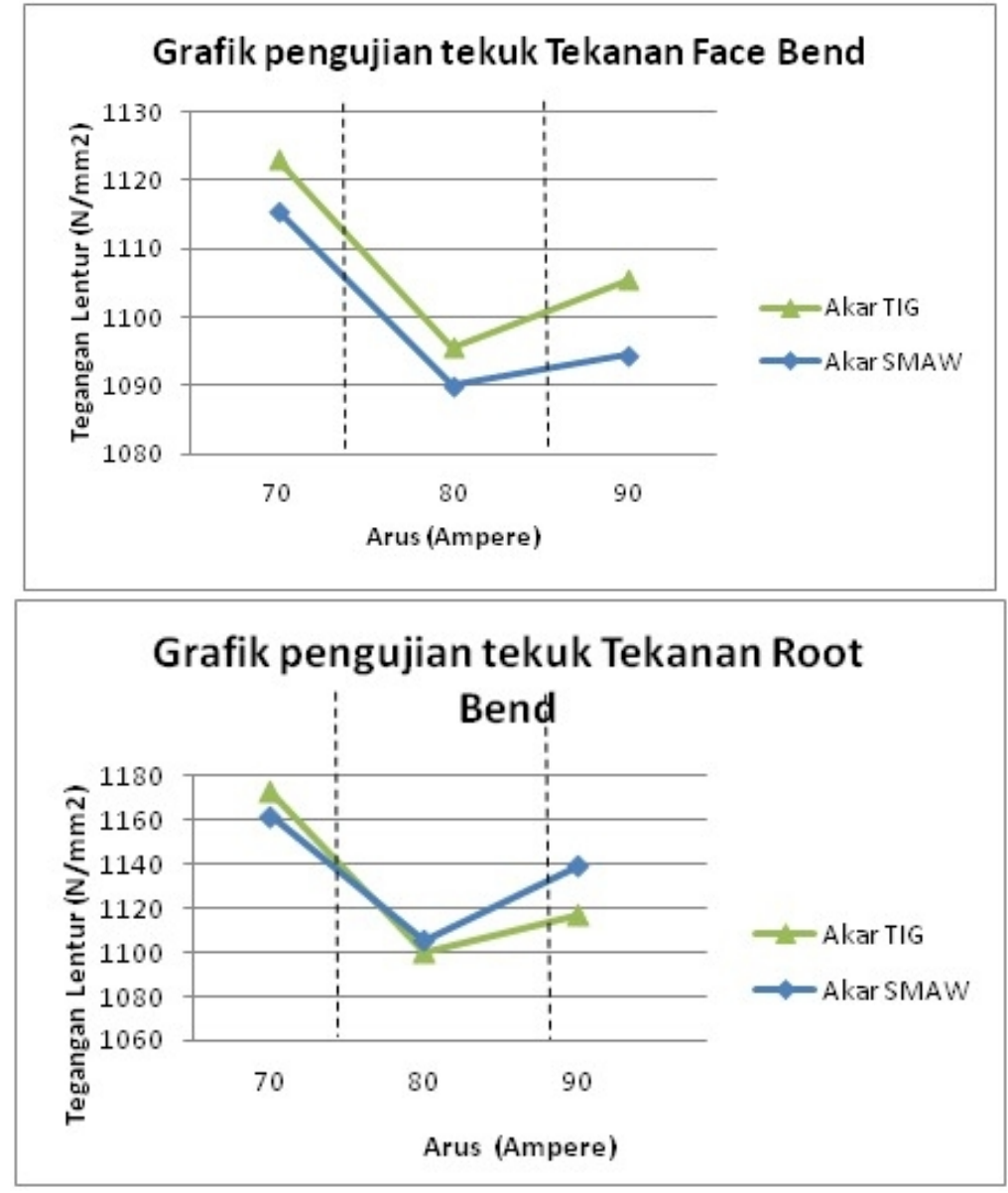

Gambar 3.4. Hubungan kuat arus dan kekuatan lentur las TIG dan SMAW

a) Root bend, b) Face bend

Regangan dan reduksi penampang dapat dilihat pada gambar 3.5.

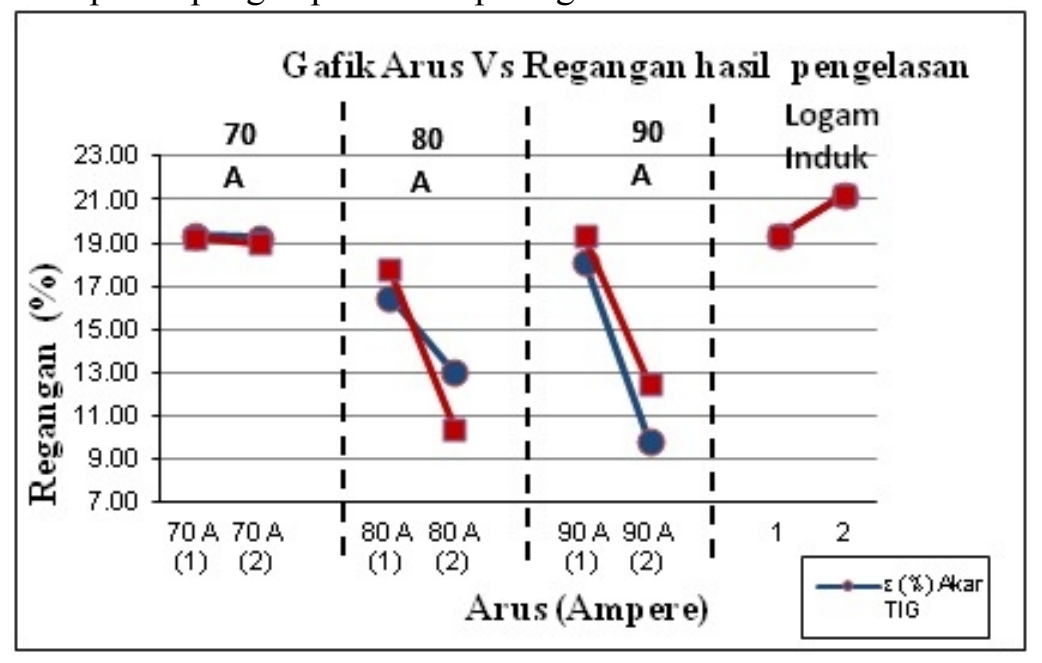


41 Muas M, Muhammad Arsyad Suyuti, Rasul, Patta Hajji. Analisis Sifat Mekanik Hasil Pengelasan SMAW dengan Akar Las Tig dan Las SMAW pada Pipa API 5 L

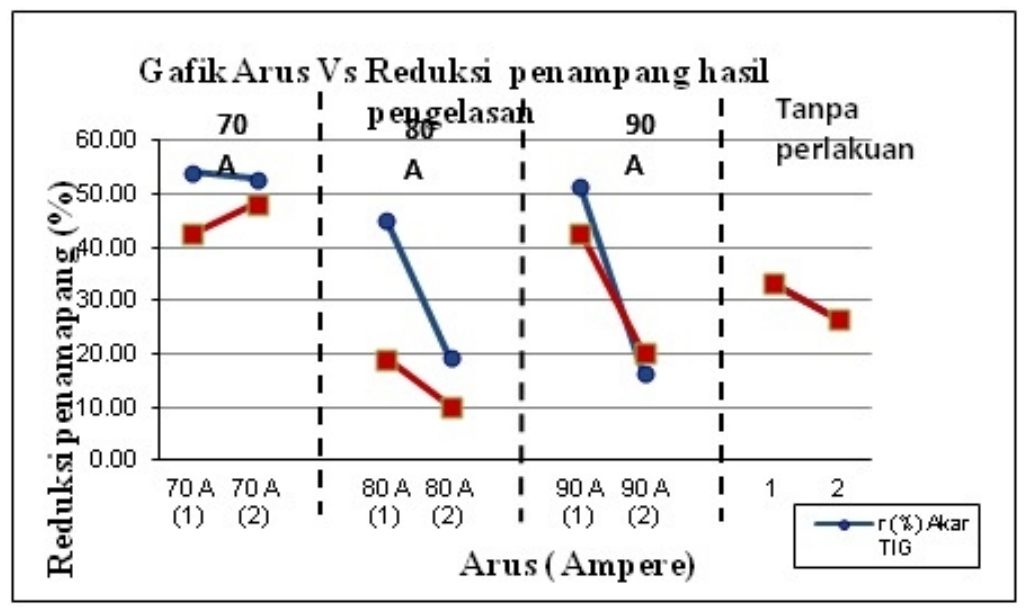

Gambar 3.5. Hubungan kuat arus, regangan dan reduksi penampang las TIG dan SMAW

a) Regangan , b) Reduksi penampang

Pengelasan pipa API 5L dengan variasi arus 70 A,80 A dan 90 A dengan akar las TIG dan akar las SMAW, arus 70 A memiliki nilai paling besar untuk kekuatan tarik, elongasi dan reduksi penampang dibandingkan arus $80 \mathrm{~A}$ dan $90 \mathrm{~A}$.

\section{KESIMPULAN}

a. Kekuatan tarik, elongasi dan reduksi penampang pada pengelasan pipa API 5L dengan akar las TIG dan SMAW memiliki nilai paling besar menggunakan arus $70 \mathrm{~A}$.

b. Pada Pengelasan dengan mengunakan akar las TIG, Kekuatan tarik sambungan las tertinggi yaitu terjadi pada Arus 70 A sebesar $52,27 \mathrm{kgf} / \mathrm{mm}^{2}$. Kekerasan tertinggi terjadi pada arus 90 A yaitu sebesar 164,217 HRB. Kekuatan lentur tertinggi terjadi pada arus 70 A yaitu sebesar 1.123,061 $\mathrm{N} / \mathrm{mm}^{2}$ untuk penekanan face bend, dan $1.172,959 \mathrm{~N} / \mathrm{mm}^{2}$ untuk penekanan root bend. Pada pengelasan dengan mengunakan akar las SMAW, kekuatan tarik sambungan las tertinggi terjadi pada arus $70 \mathrm{~A}$ yaitu sebesar $54,27 \mathrm{kgf} / \mathrm{mm}^{2}$. Kekerasan tertinggi terjadi pada arus $70 \mathrm{~A}$ yaitu sebesar 158,717 HRB.Kekuatan lentur tertinggi terjadi pada arus $70 \mathrm{~A}$ yaitu sebesar 1.115,611 $\mathrm{N} / \mathrm{mm}^{2}$ untuk penekanan face bend, dan $1.161,748 \mathrm{~N} / \mathrm{mm}^{2}$ untuk penekanan root bend

c. Pada penelitian selanjutnya disarankan untuk menambah variasi arus, melakukan pengujian metalografi dan radiografi.

\section{DAFTAR PUSTAKA}

[1] J.Santoso, "Pengaruh arus pengelasan terhadap kekuatan tarik dan ketangguhan las SMAW dengan elektroda E7018”, 2006, 25-45.

[2] Kadir,Harlian, "Petunjuk Kerja Pengelasan", Bandung: Pusat Pengembangan Pendidikan Politeknik, 1995.

[3] Schonmetz, Alois Dkk, "Pengetahuan Bahan Dalam Pengerjaan Logam", Bandung: Angkasa Bandung, 1985.

[4] Sonawan Dkk, "Pengantar Untuk Memahami Proses Pengelasan Logam", Bandung: CV. Alfabeta, 2004.

[5] Surdia Dkk, "Pengetahuan Bahan Teknik", Jakarta: PT. Pradnya Paramita, 2000.

[6] Wiryosumarto, Harsono, "Teknologi Pengelasan Logam", Jakarta: PT. Pradnya Paramita, 1996 